\title{
Benford's Law and an Analysis in Istanbul Stock Exchange (BIST)
}

\author{
Alper Karavardar ${ }^{1}$ \\ ${ }^{1}$ Business Administration Department, Faculty of Economics and Administrative Sciences, Giresun University, \\ Turkey \\ Correspondence: Alper Karavardar, Business Administration Department, Faculty of Economics and \\ Administrative Sciences, Giresun University, Turkey. E-mail: akaravardar@yahoo.com
}

Received: December 12, 2013

Accepted: March 10, $2014 \quad$ Online Published: March 21, 2014

doi:10.5539/ijbm.v9n4p160

URL: http://dx.doi.org/10.5539/ijbm.v9n4p160

\begin{abstract}
Benford's Law, which has a logaritmic base, is a simple but an effective analytical examination tool for researchers. It makes researchers determine abnormalities in numerical data clusters. Benford's Law as a numerical analytic test is a mathematical comparison which proves unnatural deviations in data analysis. For that reason, it has various application areas such as auditing and finance. Investors may use Benford's Law for finding out financial frauds and abuses. This paper aims to test stock market indexes and stock values in Istanbul Stock Exchange (BIST) whether they fellow Benford's Law of Anomalous Numbers or not. All indexes' closing values and stocks' closing values, stocks' monthly gains and losses were also examined. In this study, it was found that series of monthly gains and losses on the twenty-eight indexes reasonably agree with Benford's Law.
\end{abstract}

Keywords: Benford's Law, auditing of stocks' and indexes' values

\section{Introduction}

Capital markets' regulations are founded on simple principles. These are inspiring, confidence and transperancy, protecting investors' rights and regulating fair market conditions. These values are international standards and the first step of the investment process. Investors aim to have a minimum risk and a maximum gain by maximizing their knowledge about investments. This point of view has a incomplete or incorrect knowledge on data which is an important part of investment decisions. Under discussion of stock investments, investors aim to minimize diversifiable risk. Fundamentally, they try to express the portfolio risk as a mathematical function. At this point, main issue is stocks' data's thrustworthy. These necessities are appeared in the consequence of capital markets regulations. Many past financial crisis showed that reliable financial data is an essential issue for investment decisions.

Benford's Law is a probability distiribution. The main comment in this law is data's constancy and also its usability for different disciplines. It has been promoted by auditors because of providing a simple and an effective tool for detection of fraud. Difference between observed frequency of collecting data in specific conditions and Benford theoretical probabilty distribution can be determined by using it. In other words, any statistical test can compare the actual number of items observed to the expected items and calculates the deviation. With this property, it is a useful auditing tool. One of the Benford's Law applications area is stock investment. As a research subject, stocks' prices, gains and losses can be examined with Benford's Law. Confronting stock market data distribution and Benford's Law in a study as an application will be useful in two ways. First of all, this application can give an opinion to investors about reliability of investments' data sets. Secondly, it attracks investors for abnormal number families which have marks on specific stocks or indexes.

This paper's subject is to examine stocks' prices, stocks' montly gains and twenty-eight indexes in Istanbul Stock Exchange's (BIST) agreement with Benford's Law. Istanbul Stock Exchange (BIST) is the only international stock market where stocks and shares are bought and sold in Turkey. This paper is used monthly observations of Istanbul Stock Exchange's (BIST) all stocks' and indexes' data from January 1986 to December 2011 (included those months). First digit, second digit and first two digits tests in Turkish Liras (TL) and U.S. Dollars (USD) are done. Besides, all those tests to monthly negative and positive price differences in all stocks and indexes are done.

\subsection{Benford's (Significant Digit) Law}

In 1881, Simon Newcomb, an astromer and mathematician, published the first known two-page article that 
describes Benford's (significant digit) Law in the U.S. Journal of Mathematics. He mentioned his observations on the copies of logarithms books in the library. According to his observations, these copies were more worn at their beginning pages with low digits than the pages with higher digits. Newcomb calculated the probability as a number that has any particular non-zero first digit is:

$$
P(i)=\log 10(1+i-1)
$$

Where: "i" is a number: $1,2,3,4,5,6,7,8,9$

"P" is the probability (The first significant digit)

"Log (x)"represents the logarithm of $\mathrm{x}$ to the base 10 .

Formulas for expected digital frequencies:

For the first digit of the number:

Probability $(\mathrm{D} 1=\mathrm{d} 1)=\log 10(1+(1 / \mathrm{d} 1)) ; \mathrm{d} 1=(1,2,3,4,5,6,7,8,9)$

For the second digit of the number;

Probability $(\mathrm{D} 2=\mathrm{d} 2)=\sum_{d_{1}=1}^{9} \log _{10}(1+(1 / \mathrm{d} 1 \mathrm{~d} 2)) ; \mathrm{d} 2=(1,2,3,4,5,6,7,8,9,0)$

For two digits combinations:

Probability $(\mathrm{D} 1 \mathrm{D} 2=\mathrm{d} 1 \mathrm{~d} 2)=\log 10(1+(1 / \mathrm{d} 1 \mathrm{~d} 2))$

Probability $(\mathrm{D} 2=\mathrm{d} 2 \mid \mathrm{D} 1=\mathrm{d} 1)=\log 10(1+(1 / \mathrm{d} 1 \mathrm{~d} 2)) / \log 10(1+(1 / \mathrm{d} 1))$

Where:

D1: represents the first digit of a number.

D2: represents the second digit of a number, etc. (Newcomb, 1881).

In 1938, Frank Benford, an physicist, attempted to test Newcomb's asserts. Benford collected 20,229 observations from diverse data sets such as rivers, numbers of consecutive front page news items of a newspaper, street addresses, population data, atomic weights of elements and numbers appearing in Reader's Digest articles. He investigated 20 different areas and he came to the same conclusion with Newcomb. Benford presented a general law of anomalous numbers by an article in "Proceeding of U.S. Philosophical Society". Benford's Law is more than just the simple statement that lower numbers occupy the first digit location more frequently than higher numbers; besides, Benford broke down these occurrences into percentages for each number, one through nine, excluding zero (Johnson \& Weggenmann, 2013).

It is observed that many empirical data in the real world follow Benford's law such as stock market indices, tax returns and Fibonacci numbers (Wang, Cha, Cho, \& JayKuo, 2009). Moreover, digital analysis (also first-digit law or Benford's Law) was discussed in the professional guidance on fraud detection in general (Debreceny \& Gray, 2010). Various researchers tested this issue. Goudsmit and Furry (1944), and Furlan (1948) offered various explanations for this phenomenon. Pinkham (1961) showed a multiplication by a constant that didn't change distribution of the first digits. Raimi (1969) also examined the distribution of the first digits. In 1972, Varian, an economist, suggested that Benford' Law can be used as a test of random data in a social science context. Carslaw (1988) used Benford's Law to show that New Zealand firms' earnings' didn't conform to the Benford's expected distribution. In 1989, Thomas made a similiar examination and found similiar results in the earnings of U.S. firms. Boyle (1994) showed that why certain sets of accounting numbers often follow Benford's Law distiribution. Theodore, a mathematician, used Benford's distribution like the normal distribution and demonstrated how it was applied to stock market data, certain accounting data (Hill, 1995; 1998). He offered a new statistical derivation of the Benford's Law. Nigrini in his dissertation (published in 1992) examined on earnings manipulation with Benford's Law and used digital analysis to help identify tax evaders in 1996. The IRS in the USA now routinely uses Benford's Law as a means of highlighting anomalies and electing taxpayers to audit (Goulding, 2013). Ley and Varian (1994), Koedijk and Stork (1994) studied patterns in the digits of U.S. stock market indexes. Ley (1994) found that the series of one-day returns on the Dow-Jones Industrial Average Index (DJIA) and Standard and Poor's Index (S\&P) reasonably agrees with Benford's distribution (Goulding, 2013).

\subsection{An Analysis in Istanbul Stock Exchange Market}

In this study, stocks in Istanbul Stock Exchange Market are analysed according to the Benford's Law. This study has two parts. In the first part, monthly closing values of stocks and stocks' monthly gains according to 
their monthly closing values are analysed. In the second part, 27 indexes' closing values and monthly gains which are active stocks in Istanbul Stock Exchange Market are analysed. Examinations are based on both Turkish Lira (TL) and U.S. Dollar (USD). In addition to that, negative and positive differences are also analysed. All listed stocks between January 1986 and December 2011 are examined.

The data which are explained above are tested according to Benford's Law. The data are examined according to following tests and the framework of the study is presented in Figure 1.

- The First Digit Test.

- The Second Digit Test.

- The First Two Digits Test.

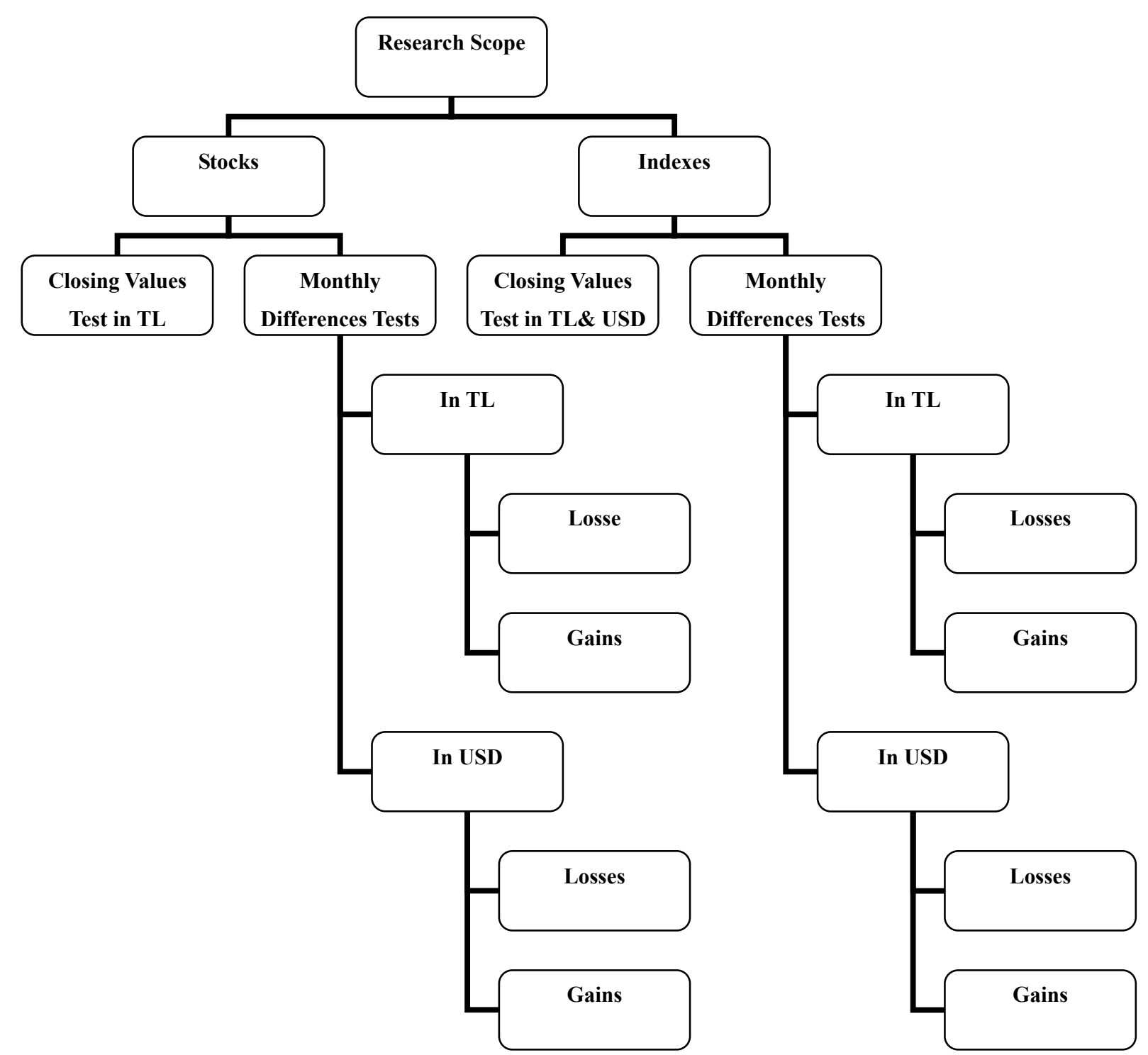

Figure 1. The Framework of the study

\section{Method}

Chi-square test for goodness of fit was used in this research. The chi-square statistics is a nonparametrzic statistical technique which is used to determine if a distribution of observed frequencies differs from the theoretical expected frequencies. The distribution of observed frequencies and the theoretical expected frequencies are Istanbul Stock Market Data and Benford's Law, respectively. Chi-square statistics use nominal (categorical) or ordinal level data, thus instead of using means and variances, this test uses frequencies. The 
Chi-square test for goodness of fit which compares the expected and observed values to determine how well an researcher's predictions fit the data (McGibbon, 2006). Goodness of fit means how well a statistical model fits a set of observations in significance level of the test. A measure of goodness of fit typically summarizes the discrepancy between observed values and the values expected under the model in question. The chi-square test is defined for the hypothesis (Bowen, Starr, \& Martin, 1982):

H0: The data follow a specified distribution. (Istanbul Stock Market data follow Benford's Law)

H1: The data do not follow a specified distribution. (Istanbul Stock Market data don't follow Benford's Law)

Test Statistics: $\chi 2=\sum(\mathrm{Oi}-\mathrm{Ei}) 2 / \mathrm{Ei}$

Oi: Number of observed cases in each categories.

Ei: Number of expected cases in each categories.

Decision Rule:

$\alpha$ : Significance level of the test

$v$ : Degrees of freedom

Reject $\mathrm{H} 0$ if sample $\chi^{2}>\chi 2 \alpha$,

Chi Square tests and $\mathrm{z}$ statistics are used to evaluate the compability degrees of each category's expectations and observations. Besides this, chi square tests and $\mathrm{z}$ statistics are also elicitid to show that there is no tendency in gain amounts.

\section{Results}

The test of monthly closing values of stocks in TL, monthly losses and gains of stocks in TL, monthly gains of stocks in USD, closing values of indexes, monthly losses and gains of indexes are presented in this section.

\subsection{Tests of Monthly Closing Values of Stocks in TL}

In this section, stocks are tested by the first digit, the second digit and the first two digits of Benford's Law. These results aren't conformable to Benford's Law. Test results are shown in Figure 2, Figure 3 and Figure 4.

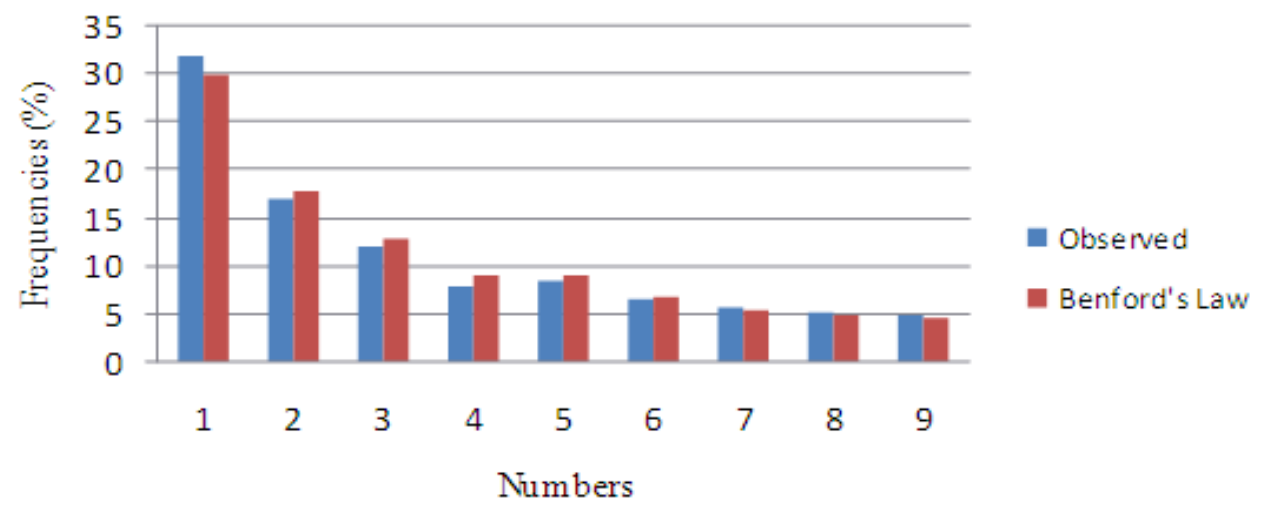

Figure 2. The first digit test of stocks' monthly closing prices

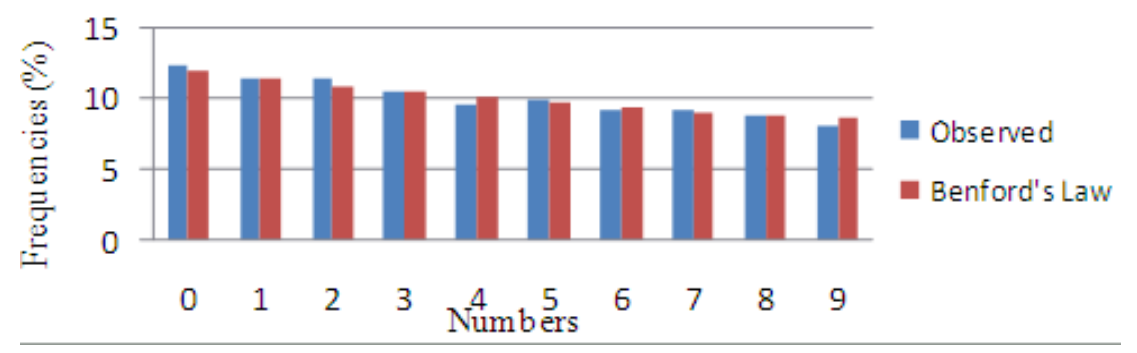

Figure 3. The second digit test of stocks' monthly closing prices 


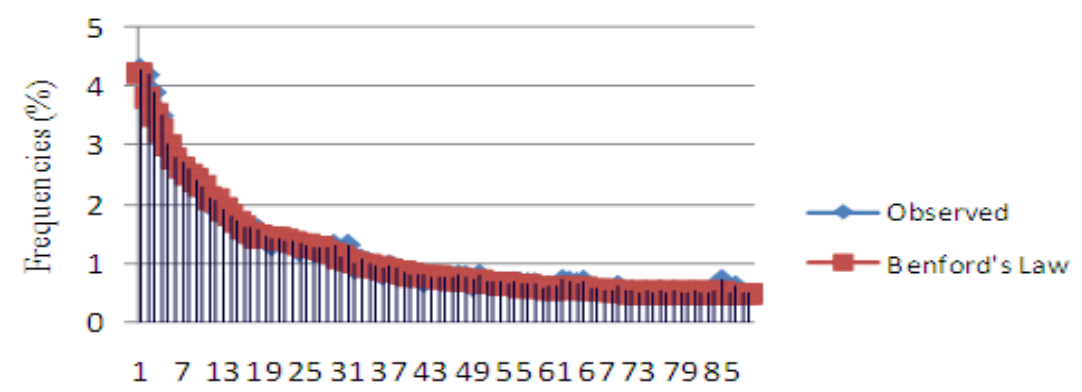

Numbers

Figure 4. The first two digit test of stocks' monthly closing prices

\subsection{Tests of Monthly Losses and Gains of Stocks in TL}

In this section, test of negative differences (monthly losses) and tests of positive differences (monthly gains) in TL will be presented.

\subsubsection{Test of Negative Differences (Monthly losses)}

Monthly negative differences which are calculated by using stocks' closing values in TL in Istanbul Stock Exchange Market aren't conformable to the Benford's Law for the first digit test, the second digit test, and the first two digits test. Test results are presented in Figure 5, Figure 6 and Figure 7. Each monthly loss is calculated based on the previous month.

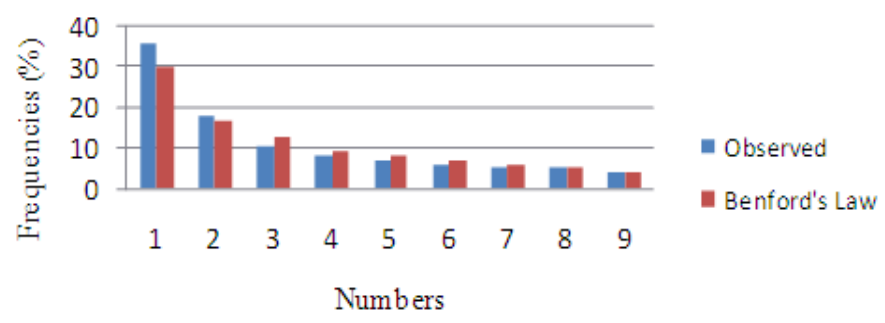

Figure 5. The first digit test of stocks' monthly losses in TL

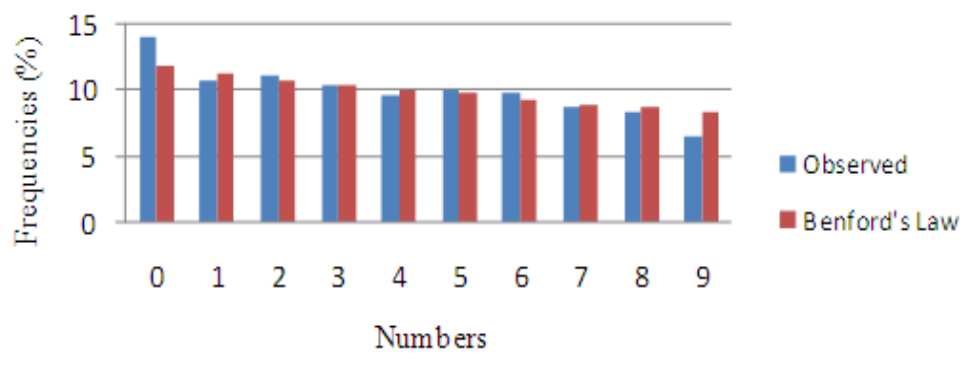

Figure 6. The second digit test of stocks' monthly losses in TL 


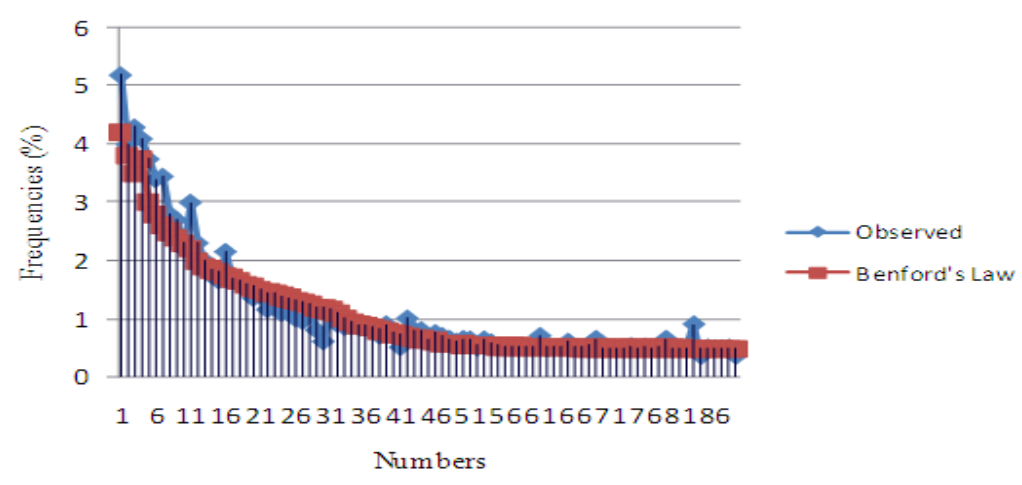

Figure 7. The first two digits test of stocks' monthly losses in TL

\subsubsection{Tests of Positive Differences (Monthly Gains)}

Monthly positive differences which are calculated by using stocks' closing values in TL in Istanbul Stock Exchange Market aren't conformable to the Benford's Law for the first digit test, the second digit test, and the first two digits test. Test results are presented in Figure 8., Figure 9. and Figure 10. Each monthly gain is calculated based on the previous month

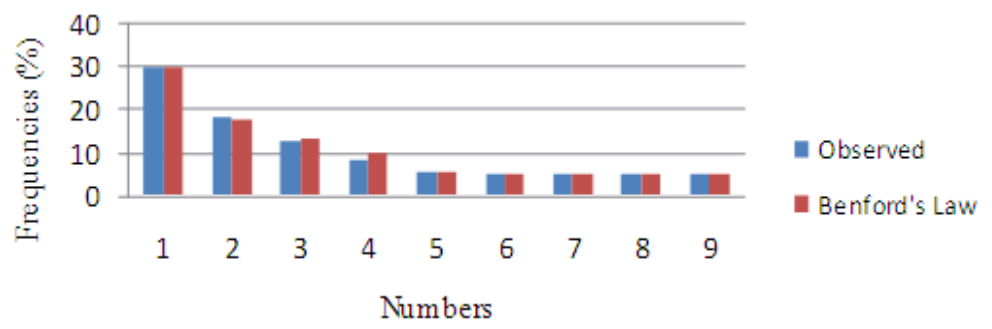

Figure 8. The First Digit Test of Stocks' Monthly Gains in TL

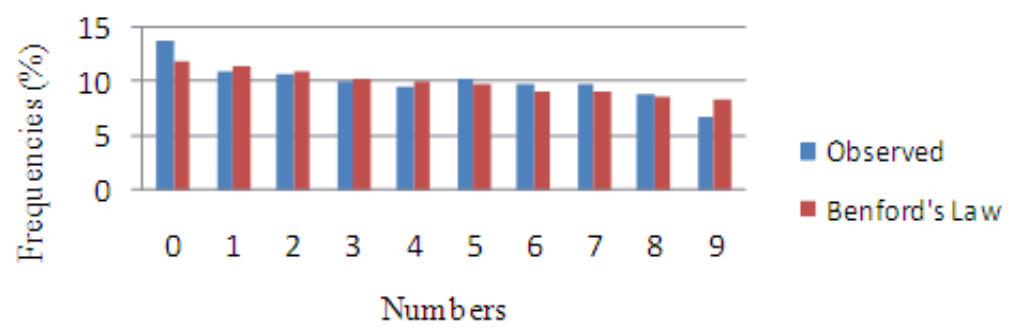

Figure 9. The second test of stocks' monthly gains in tl

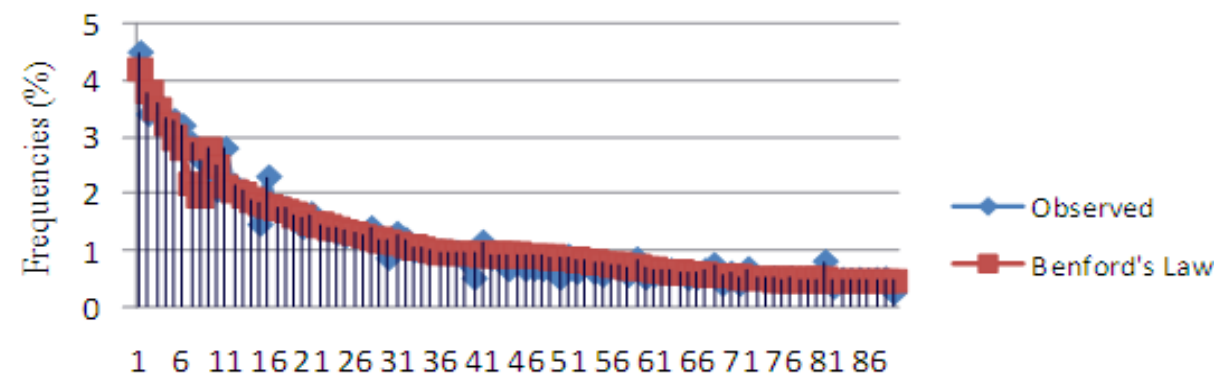

Numbers

Figure 10. The first two digits test of stocks' monthly gains in tl 


\subsection{Tests of Monthly Gains of Stocks in USD}

In this section, test of negative differences (monthly losses) and test of positive differences (monthly gains) in USD will be examined.

\subsubsection{Test of Negative Differences (Monthly losses)}

Monthly negative differences which are calculated by using stocks' closing values in USD in Istanbul Stock Exchange Market aren't conformable to the Benford's Law for the first digit test, and the first two digit tests, however they are conformable to the second digit tests. Test results are presented in Figure 11, Figure 12, and Figure 13. Each monthly loss is calculated based on the previous month.

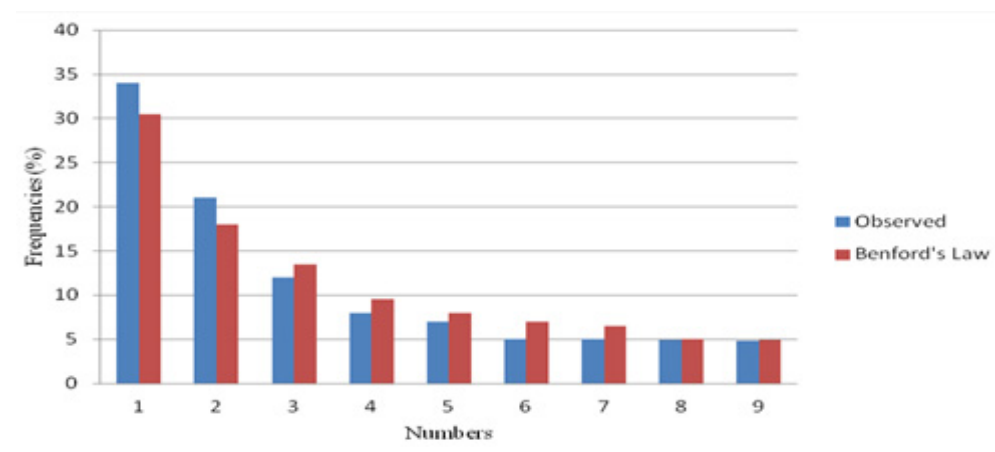

Figure 11. The first digit test of stocks' monthly losses in USD

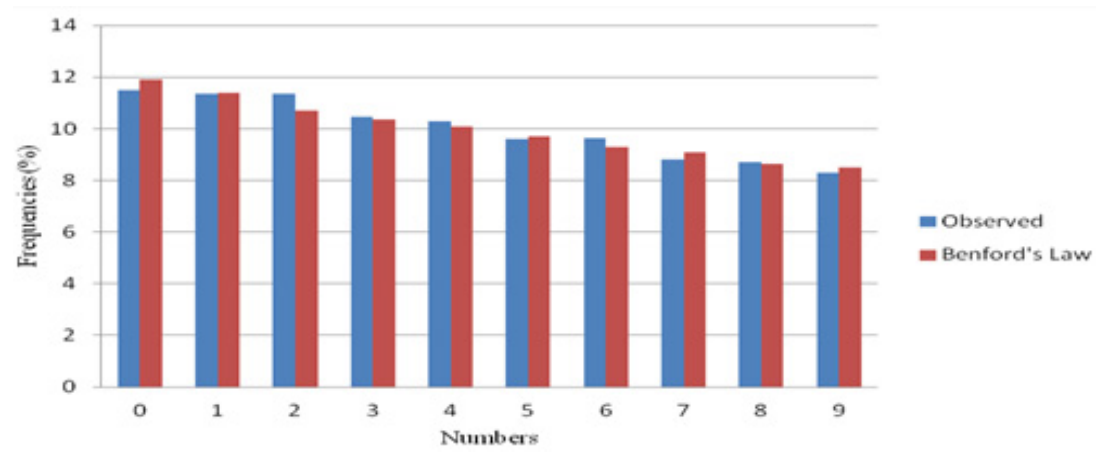

Figure 12. The second digit test of stocks' monthly losses in USD

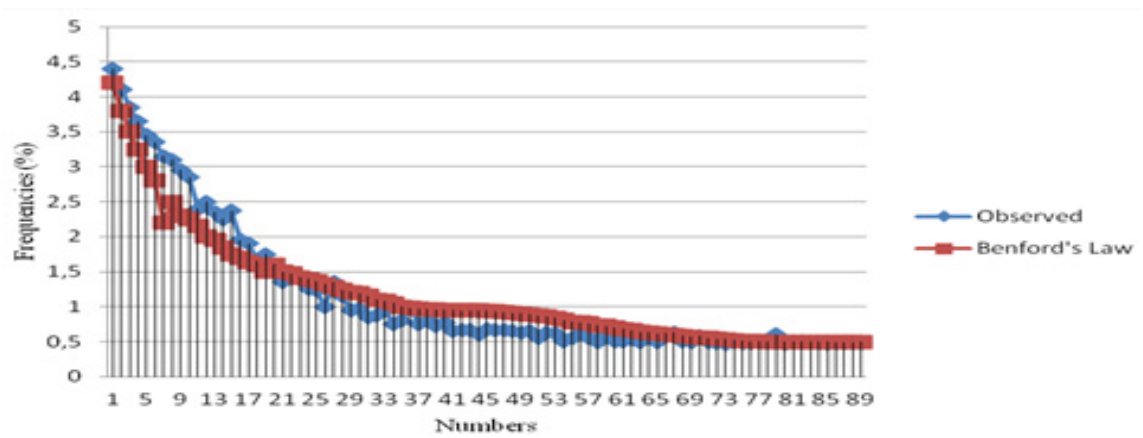

Figure 13. The first two digits test of stocks' monthly losses in USD

\subsubsection{Test of Positive Differences (Monthly Gains)}

Monthly positive differences which are calculated by using stocks' closing values in USD in Istanbul Stock Exchange Market aren't conformable to the Benford's Law for the first digit test. However, they are 
conformable to the second digit tests and the first two digit tests. Test results are presented in Figure 14, Figure 15 and Figure 16. Each monthly gain is calculated based on the previous month.

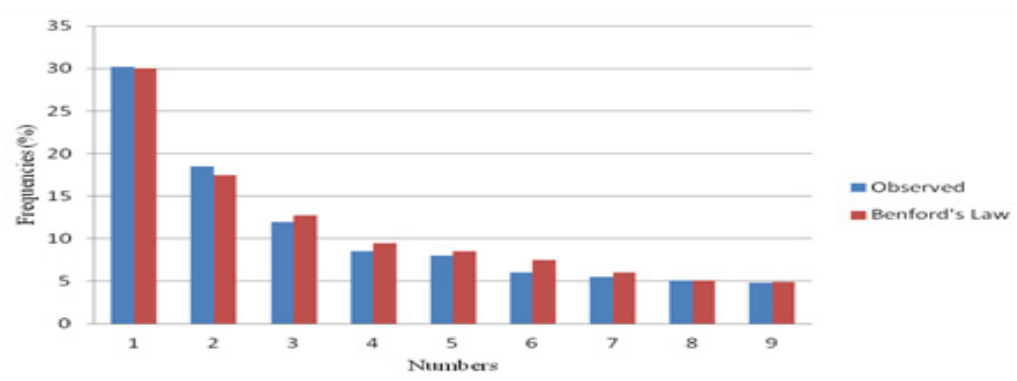

Figure 14. The first digit test of stocks' monthly gains in USD

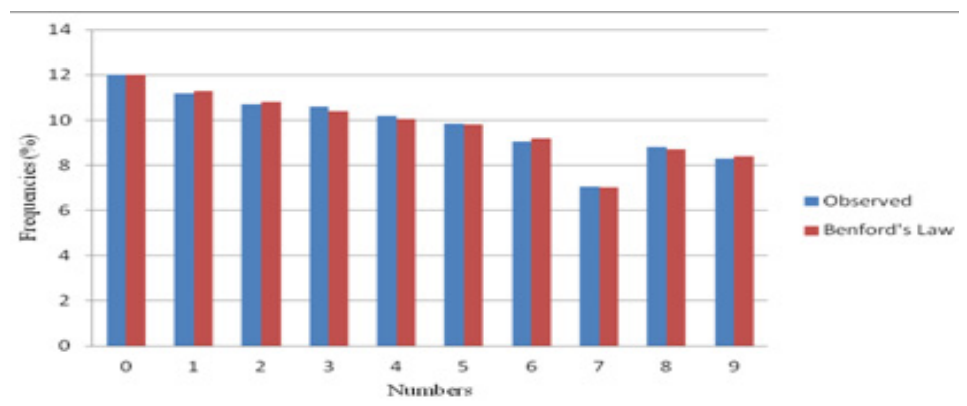

Figure 15. The second digit test of stocks' monthly gains in USD

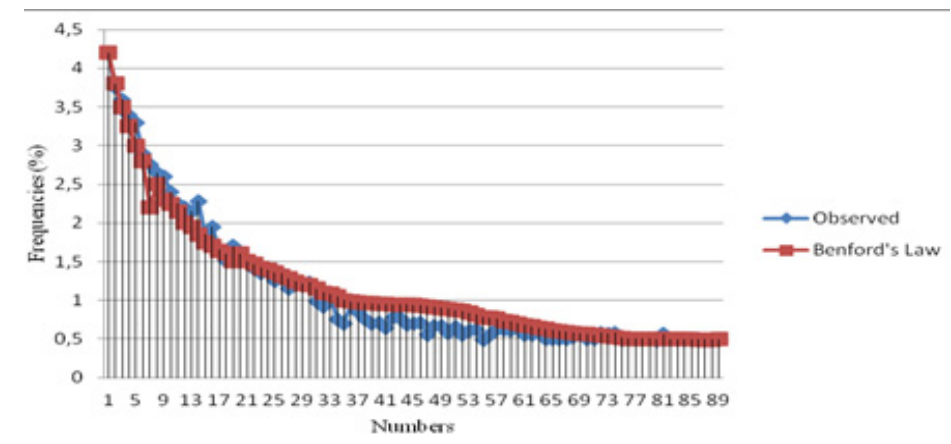

Figure 16. The first two digits test of stocks' monthly gains in USD

\subsection{Tests of Closing Values of Indexes}

Each index which has active stocks in Istanbul Stock Exchange Market is analysed (confidence interval is both $1 \%$ and $5 \%$ ) in both TL and USD. Following table (Table 1.) summarizes results of the tests. According to the table, monthly closing values of indexes aren't conformable to the Benforf Law for both in TL and USD. As it can be seen in the Table 1, only the second digit tests are conformable to the Benford's Law in certain indexes. (Different results have been showed with bold characters). 
Table 1. Chi Square values of indexes' closing values

\begin{tabular}{|c|c|c|c|c|}
\hline \multicolumn{5}{|c|}{ Chi-Square Values } \\
\hline Index Name & Base Currency & The First Digit Test & The Second Digit Test & The First Two Digits Test \\
\hline \multirow{2}{*}{ XBANK } & TL base & 305,65 & 52,87 & 615,21 \\
\hline & USD base & 146,02 & 47,14 & 481,18 \\
\hline \multirow{2}{*}{ XBLSM } & TL base & 3059,25 & 6,01 & 4131,10 \\
\hline & USD base & 1748,33 & 111,89 & 2766,55 \\
\hline \multirow{2}{*}{ XELKT } & TL base & 1764,16 & 241,03 & 4150,15 \\
\hline & USD base & 2117,84 & 58,04 & 2629,81 \\
\hline \multirow{2}{*}{ XFINK } & TL base & 510,58 & 58,59 & 950,21 \\
\hline & USD base & 928,38 & 55,20 & 1350,02 \\
\hline \multirow{2}{*}{ XGIDA } & TL base & 577,99 & 159,11 & 1091,41 \\
\hline & USD base & 496,05 & 66,67 & 1006,42 \\
\hline \multirow{2}{*}{ XGMYO } & TL base & 1129,05 & 60,73 & 1517,46 \\
\hline & USD base & 637,74 & 85,09 & 947,99 \\
\hline \multirow{2}{*}{ XHOLD } & TL base & 971,47 & 131,74 & 1349,40 \\
\hline & USD base & 769,65 & 79,96 & 1208,44 \\
\hline \multirow{2}{*}{ XILTM } & TL base & 557,52 & 80,31 & 1336,51 \\
\hline & USD base & 1005,37 & 20,48 & 1353,38 \\
\hline \multirow{2}{*}{ XKAGT } & TL base & 1035,42 & 38,41 & 1292,95 \\
\hline & USD base & 718,89 & 55,41 & 1281,10 \\
\hline \multirow{2}{*}{ XKMYA } & TL base & 1057,47 & 77,41 & 1353,87 \\
\hline & USD base & 982,97 & 58,59 & 1602,66 \\
\hline \multirow{2}{*}{ XMANA } & TL base & 712,48 & 13,30 & 1081,75 \\
\hline & USD base & 352,16 & 90,05 & 703,78 \\
\hline \multirow{2}{*}{ XMESY } & TL base & 1560,31 & 65,97 & 2345,00 \\
\hline & USD base & 1118,34 & 94,84 & 1635,85 \\
\hline \multirow{2}{*}{ XSGRT } & TL base & 326,85 & 52,70 & 562,98 \\
\hline & USD base & 296,69 & 13,08 & 636,51 \\
\hline \multirow{2}{*}{ XSVNM } & TL base & 337,51 & 102,24 & 909,43 \\
\hline & USD base & 386,40 & 181,49 & 967,66 \\
\hline \multirow{2}{*}{ XTAST } & TL base & 450,81 & 91,29 & 1031,39 \\
\hline & USD base & 383,81 & 24,18 & 761,70 \\
\hline \multirow{2}{*}{ XTCRT } & TL base & 434,46 & 32,26 & 1029,83 \\
\hline & USD base & 488,13 & 46,24 & 831,59 \\
\hline \multirow{2}{*}{ XTEKS } & TL base & 2124,81 & 60,16 & 2923,24 \\
\hline & USD base & 1169,01 & 86,01 & 2385,91 \\
\hline \multirow{2}{*}{ XTRZM } & TL base & 222,59 & 73,15 & 583,72 \\
\hline & USD base & 99,28 & 92,92 & 445,11 \\
\hline \multirow{2}{*}{ XU030 } & TL base & 477,30 & 71,42 & 929,57 \\
\hline & USD base & 368,49 & 55,05 & 775,05 \\
\hline \multirow{2}{*}{ XU050 } & TL base & 474,97 & 16,51 & 1024,46 \\
\hline & USD base & 317,69 & 48,98 & 802,16 \\
\hline XU100 & TL base & 1542,26 & 88,49 & 2539,13 \\
\hline (1) & USD base & 791,17 & 75,46 & 1570,26 \\
\hline XUHIZ & TL base & 300,70 & 43,86 & 779,03 \\
\hline AUTHZ & USD base & 774,21 & 71,84 & 1262,06 \\
\hline $\mathrm{YUU} \triangle \mathrm{S}$ & TL base & 874,20 & 89,31 & 1459,94 \\
\hline AULAS & USD base & 1547,55 & 20,50 & 1779,16 \\
\hline YIMAI & TL base & 639,01 & 81,00 & 1229,10 \\
\hline XUIMAL & USD base & 303,35 & 174,52 & 773,75 \\
\hline XUSIN & TL base & 1078,86 & 129,15 & 1993,16 \\
\hline
\end{tabular}




\begin{tabular}{lllll}
\hline & USD base & 2373,33 & 81,78 & 2893,20 \\
XUTEK & TL base & 1742,72 & 283,45 & 3076,74 \\
& USD base & 1272,17 & 91,36 & 1710,46 \\
XUTUM & TL base & 532,84 & $\mathbf{2 0 , 1 1}$ & 1007,62 \\
& USD base & 495,55 & 25,78 & 841,94 \\
XYORT & TL base & 876,00 & 293,06 & 1944,27 \\
& USD base & 2370,67 & 55,87 & 2839,36 \\
\hline
\end{tabular}

\subsection{Tests of Monthly Losses and Gains of Indexes}

Tests of monthly losses and gains of indexes in Istanbul Stock Exchange Market in both TL and USD are done. Results can be seen in the Table 2. As it can be seen from the table, most of the indexes are conformable to the Benford's Law in TL and USD base. The noteworthy point of two indexes is namely the defence index and the communication index. Those two indexes aren't conformable to the Benford's Law in TL base. Twelve indexes have divergences from Benford's Law in different base (TL and USD) and different tests (First, second and first two digits). According to the test results fourteen indexes are entirely conformable to the Benford's Law for declared confidence interval. (Different results have been showed with bold characters).

Table 2. Chi Square values of monthly losses/gains of indexes

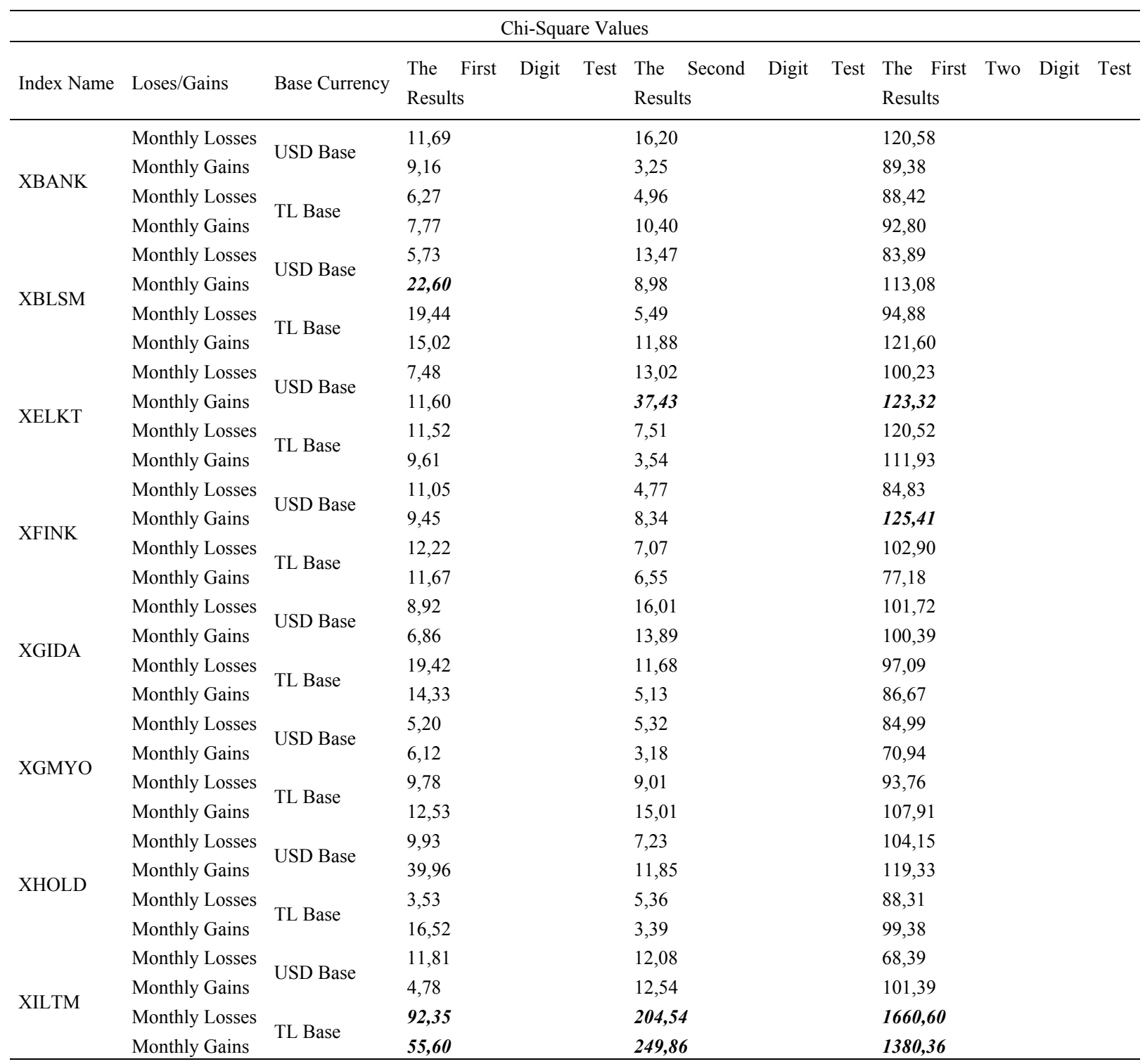




\begin{tabular}{|c|c|c|c|c|c|}
\hline \multirow{4}{*}{ XKAGT } & Monthly Losses & \multirow{2}{*}{ USD Base } & 9,76 & 3,91 & 98,70 \\
\hline & Monthly Gains & & 30,74 & 9,11 & 106,53 \\
\hline & Monthly Losses & \multirow{2}{*}{ TL Base } & 14,46 & 7,43 & 94,25 \\
\hline & Monthly Gains & & 23,60 & 14,75 & 106,21 \\
\hline \multirow{4}{*}{ XKMYA } & Monthly Losses & \multirow{2}{*}{ USD Base } & 7,33 & 9,62 & 71,85 \\
\hline & Monthly Gains & & 9,42 & 12,54 & 98,53 \\
\hline & Monthly Losses & \multirow{2}{*}{ TL Base } & 14,12 & 7,41 & 84,10 \\
\hline & Monthly Gains & & 15,86 & 8,95 & 90,16 \\
\hline \multirow{4}{*}{ XMANA } & Monthly Losses & \multirow{2}{*}{ USD Base } & 7,11 & 17,68 & 82,26 \\
\hline & Monthly Gains & & 13,16 & 11,77 & 105,48 \\
\hline & Monthly Losses & \multirow{2}{*}{ TL Base } & 8,20 & 5,09 & 84,65 \\
\hline & Monthly Gains & & 5,39 & 5,55 & 67,56 \\
\hline \multirow{4}{*}{ XMESY } & Monthly Losses & \multirow{2}{*}{ USD Base } & 11,97 & 11,23 & 89,17 \\
\hline & Monthly Gains & & 27,96 & 3,03 & 96,79 \\
\hline & Monthly Losses & \multirow{2}{*}{ TL Base } & 18,85 & 10,61 & 115,38 \\
\hline & Monthly Gains & & 27,28 & 10,98 & 122,50 \\
\hline \multirow{4}{*}{ XSGRT } & Monthly Losses & \multirow{2}{*}{ USD Base } & 10,56 & 4,77 & 86,70 \\
\hline & Monthly Gains & & 6,25 & 13,03 & 76,13 \\
\hline & Monthly Losses & \multirow{2}{*}{ TL Base } & 5,97 & 13,08 & 91,89 \\
\hline & Monthly Gains & & 18,17 & 6,59 & 83,30 \\
\hline \multirow{4}{*}{ XSVNM } & Monthly Losses & \multirow{2}{*}{ USD Base } & 12,35 & 15,57 & 85,55 \\
\hline & Monthly Gains & & 6,26 & 5,18 & 78,03 \\
\hline & Monthly Losses & \multirow{2}{*}{ TL Base } & 196,66 & 645,34 & 4922,13 \\
\hline & Monthly Gains & & 181,34 & 649,02 & 4644,58 \\
\hline & Monthly Losses & & 1,04 & 4,33 & 84,67 \\
\hline XTAST & Monthly Gains & UsD base & 10,05 & 13,67 & 84,31 \\
\hline AIADI & Monthly Losses & & 10,56 & 9,97 & 88,29 \\
\hline & Monthly Gains & 1L Base & 18,75 & 8,51 & 101,72 \\
\hline & Monthly Losses & USD Base & 2,83 & 11,86 & 92,22 \\
\hline XTCRT & Monthly Gains & USD base & 6,12 & 8,99 & 73,43 \\
\hline XICR & Monthly Losses & TI Rase & 16,65 & 12,58 & 122,14 \\
\hline & Monthly Gains & 1L Base & 6,46 & 6,47 & 90,54 \\
\hline & Monthly Losses & USD Base & 19,36 & 12,25 & 108,39 \\
\hline XTFKS & Monthly Gains & USD Base & 24,17 & 15,58 & 103,08 \\
\hline XIEKS & Monthly Losses & TI Posa & 7,79 & 5,91 & 89,08 \\
\hline & Monthly Gains & IL Base & 19,13 & 8,84 & 100,72 \\
\hline & Monthly Losses & ISS Rase & 5,19 & 7,06 & 81,80 \\
\hline XTP7M & Monthly Gains & USD Base & 6,38 & 19,96 & 85,53 \\
\hline XIRZIVI & Monthly Losses & & 7,39 & 10,41 & 84,90 \\
\hline & Monthly Gains & TL Base & 8,55 & 11,11 & 79,30 \\
\hline & Monthly Losses & ISS Rase & 6,95 & 10,25 & 79,95 \\
\hline XU 030 & Monthly Gains & USD Base & 19,48 & 18,18 & 99,95 \\
\hline XU030 & Monthly Losses & TI Pase & 10,95 & 9,81 & 64,74 \\
\hline & Monthly Gains & 1L Base & 15,32 & 4,00 & 116,76 \\
\hline & Monthly Losses & USD Rase & 6,20 & 10,01 & 76,33 \\
\hline XUU50 & Monthly Gains & USD base & 12,29 & 7,40 & 86,97 \\
\hline$x 0050$ & Monthly Losses & TI Rase & 9,86 & 8,81 & 84,54 \\
\hline & Monthly Gains & IL Base & 19,43 & 13,05 & 119,34 \\
\hline & Monthly Losses & & 10,34 & 10,47 & 95,35 \\
\hline YII100 & Monthly Gains & USD Base & 8,91 & 9,21 & 82,28 \\
\hline$x \cup 100$ & Monthly Losses & TI Base & 8,14 & 57,29 & 153,02 \\
\hline & Monthly Gains & 1L Base & 7,95 & 64,38 & 143,66 \\
\hline & Monthly Losses & JISD Base & 6,17 & 8,11 & 90,30 \\
\hline ХUHIZ & Monthly Gains & USD Base & 16,91 & 5,30 & 93,53 \\
\hline AUח⿰氵工 & Monthly Losses & TI Rase & 22,96 & 10,78 & 99,24 \\
\hline & Monthly Gains & 1L Base & 16,61 & 14,10 & 92,63 \\
\hline
\end{tabular}




\begin{tabular}{|c|c|c|c|c|c|}
\hline \multirow{4}{*}{ XULAS } & Monthly Losses & \multirow{2}{*}{ USD Base } & 4,61 & 10,09 & 72,41 \\
\hline & Monthly Gains & & 13,34 & 9,51 & 89,08 \\
\hline & Monthly Losses & \multirow{2}{*}{ TL Base } & 19,49 & 15,95 & 130,97 \\
\hline & Monthly Gains & & 7,40 & 7,12 & 74,40 \\
\hline \multirow{4}{*}{ XUMAL } & Monthly Losses & \multirow{2}{*}{ USD Base } & 21,74 & 8,43 & 92,89 \\
\hline & Monthly Gains & & 9,48 & 7,36 & 74,46 \\
\hline & Monthly Losses & \multirow{2}{*}{ TL Base } & 23,99 & 4,43 & 92,74 \\
\hline & Monthly Gains & & 16,25 & 15,81 & 119,39 \\
\hline \multirow{4}{*}{ XUSIN } & Monthly Losses & \multirow{2}{*}{ USD Base } & 37,85 & 17,58 & 117,98 \\
\hline & Monthly Gains & & 10,92 & 8,06 & 92,98 \\
\hline & Monthly Losses & \multirow{2}{*}{ TL Base } & 19,78 & 8,87 & 90,04 \\
\hline & Monthly Gains & & 11,98 & 20,71 & 111,34 \\
\hline \multirow{4}{*}{ XUTEK } & Monthly Losses & \multirow{2}{*}{ USD Base } & 12,41 & 8,41 & 90,76 \\
\hline & Monthly Gains & & 20,64 & 3,32 & 95,30 \\
\hline & Monthly Losses & \multirow{2}{*}{ TL Base } & 13,96 & 8,85 & 80,01 \\
\hline & Monthly Gains & & 24,39 & 7,84 & 108,92 \\
\hline \multirow{4}{*}{ XUTUM } & Monthly Losses & \multirow{2}{*}{ USD Base } & 18,96 & 8,99 & 109,34 \\
\hline & Monthly Gains & & 13,78 & 3,82 & 88,35 \\
\hline & Monthly Losses & \multirow{2}{*}{ TL Base } & 6,41 & 7,85 & 89,30 \\
\hline & Monthly Gains & & 12,95 & 8,93 & 99,00 \\
\hline \multirow{4}{*}{ XYORT } & Monthly Losses & \multirow{2}{*}{ USD Base } & 11,07 & 11,72 & 95,32 \\
\hline & Monthly Gains & & 11,61 & 19,72 & 96,04 \\
\hline & Monthly Losses & \multirow{2}{*}{ TL Base } & 7,13 & 10,84 & 86,58 \\
\hline & Monthly Gains & & 8,42 & 11,80 & 83,11 \\
\hline
\end{tabular}

\section{Discussion}

Benford's Law is used to confirm the data which is thought to be formed artificially in a data cluster. Benford's Law is a distribution used by researchers to identify fictitious populations of numbers. For that reason, this law mostly used to find out frauds in auditing. Benford's Law is a probability distribution. In this study, active stocks in Istanbul Stocks Exchange Market are tested. According to the tests results, some important differences are found in two indexes in TL. The other indexes in Istanbul Stocks Exchange Market are conformable to Benford's Law for the first digit, the second digit and the first two digits tests in both TL and USD in monthly losses and monthly gains. Besides, some other tests are done on stocks' prices. According to test results, these stocks are conformable to the Benford's Law for the second digit test.

The results of this study are noteworthy for researches in the following points: After examining monthly losses/gains of indexes, two indexes were found noteworthy. The probability of artificially interference in the defence index and the communication index is highly possible in TL base. The companies' stocks in these indexes could be inspected in detail by Capital Markets Board. It can be recommended that the investors can make their investments in any indexes except these two ones. Closing values of indexes do not follow the Benford distiribution. Seven indexes conformable to the Benford's Law in the second digit tests. Therefore, they can not be classified in to the group of "outlaw numbers without known relationship". After testing the stocks' prices of Istanbul Stocks Exchange Market, it was found that they aren't conformable to the Benford's Law in general. Besides this, if Benford's Law and Istanbul Stocks Exchange Market's data are analysed together in graphics, it can be seen that both curves are very close to each other. In this study, expected and observed frequencies are compared by chi square tests and obtained negative results. However, the graphics are highly similar. Especially, the second digit tests are conformable to Benford's Law.

In this study, the patterns of stock market indexes are focused. Fourteen indexes of twenty-eight indexes in Istanbul Stocks Exchange Market are entirely conformable to the Benford's Law in confidence interval (1\% and $5 \%$ ). Twelve indexes have small disparity but it can be concluded that, in generally, they are conformable to to the Benford's Law of Anomalous Numbers. According to these results, it can be said that these companies' stocks' prices are reflecting the reality.

\section{References}

Bowen, E. K., \& Starr, M. L. (1982). Basic Statistics For Business and Economics. London: McGraw-Hill 
International Editions.

Boyle, J. (1994). An Application of Fourier Series to the Most Significant Digit Problem. U.S. Mathematical Monthly, 101(89), 879-886. http://dx.doi.org/10.2307/2975136

CarsLaw, C. A. (1988). Anomalies in Income Numbers: Evidence of Goal Oriented Behavior. The Accounting Review, 63(2), 321-327.

Debreceny, R. S., \& Gray, G. L. (2010). Data mining journal entries for fraud detection: An exploratory study. International Journal of Accounting Information Systems, 11, 157-181. http://dx.doi.org/10.1016/j.accinf.2010.08.001

Furlan, L. V. (1948). Das Harmoniegesets der Statistik: Eine Untersuchung uber die metrische Interdependenz der sozialen Erscheinungen. Beihefte zum Assekuranzjahrbuch. Verlag f'ur Recht und Gesellschaft Verlag fur Recht und Gesellschaft, A. G., Basel, Switzerland.

Goudsmit, S. A., \& Furry, W. H. (1944). Significant Figures of Numbers in Statistical Tables. Nature, 154, 800-801. http://dx.doi.org/10.1038/154800a0

Goulding, K. (2013). Benford's Law a Useful Tool for Accountants. Fraud Detection Accountancy Ireland, 45(6), 28-30.

Hill, T. P. (1995). A Statistical Derivation of the Significant Digit Law. Statistical Science, 10(4), 354-363.

Hill, T. P. (1998). The First Digital Phenomenon. U.S. Scientist, 86(4), 358-363. http://dx.doi.org/10.1511/1998.31.815

Johnson, G. G., \& Weggenmann, J. (2013). Exploratory Research Applying Benford's Law to Selected Balances in the Financial Statements of State Governments. Academy of Accounting and Financial Studies Journal, $17(3), 31-44$.

Koedijk, K. G., \& Stork, P. A. (1994). Should we care? Psychological Barriers in Stock Markets. Economic Letters, 44(4), 427-432. http://dx.doi.org/10.1016/0165-1765(94)90116-3

Ley, E. (1994). On the Peculiar Distribution of the U.S. Stock Indexes' Digits. Resources For the Future, 1-8.

Ley, E., \& Varian, H. R. (1994). Are there Psychological Barriers in the Dow-Jones Index? Applied Financial Economics, 4, 217-224. http://dx.doi.org/10.1511/1998.31.815

McGibbon, C. A. (2012). Statistical Resources. Retrieved from http://www.stats-consult.com/tutorial-10/tutorial-10.html

Newcomb, S. (1881). Note on the Frequncy of the Use of Digits in Natural Numbers. U.S. Journal of Mathematics, 4, 39-40.

Nigrini, M. J. (1996). Taxpayer Compliance Application of Benford's Law. Journal of the U.S. Taxation Association, 18(1), 72-92.

Pinkham, R. S. (1961). On The Distribution of First Significant Digits. Annals of Mathematical Statistics, 32, 1223-1230. http://dx.doi.org/10.1214/aoms/1177704862

Raimi, R. A. (1969). The Peculiar Distiribution of First Digits. Scientific U.S., 221(6), 109-120. http://dx.doi.org/10.1038/scientificamerican1269-109

Thomas, J. K. (1989). Unusual Patterns in Reported Earnings. The Accounting Review, 64(4), 773-787.

Varian, H. R. (1972). Benford's Law. The U.S. Statistician, 26, 65-66.

Wang, J., Cha, B., Cho, S. E., \& JayKuo, C. C. (2009). Understanding Benford's Law and its Vulnerability in Image Forensics. ICME 2009.

\section{Copyrights}

Copyright for this article is retained by the author(s), with first publication rights granted to the journal.

This is an open-access article distributed under the terms and conditions of the Creative Commons Attribution license (http://creativecommons.org/licenses/by/3.0/). 